\title{
German scientists may escape fraud trial
}

[MUNICH] Prosecutors in Germany are finding it more difficult than expected to bring legal charges against two scientists alleged to have perpetrated Germany's biggest ever scientific fraud.

More than a year after a scientific investigation committee concluded that clinical researcher Friedhelm Herrmann and his colleague, molecular biologist Marion Brach, had systematically fabricated data in 37 publications - and nearly two years after the affair first came to light (see Nature 387, 442; 1997) — no case has been brought to court.

Brach, who worked - and lived - with Herrmann at Harvard, Freiburg and Berlin before parting from him in 1996 to go to the University of Lübeck, has admitted fabricating data. Herrmann, who moved to the University of Ulm in 1996, continues to maintain his innocence, placing full blame on Brach.

Brach was dismissed as full professor in 1997. She is now reported to be working in New York, and is only communicating with investigators through her solicitor. Herrmann resigned his position in Ulm last month and is now working as a private practitioner in Munich.

Public prosecutors in three regions began investigating different aspects of the affair last year. Those for the state of Baden-Württemberg, Herrmann's formal employer at the University of Ulm, had hoped to take disciplinary action against him on the grounds that evidence that he perpetrated fraud made him "unsuitable" for employment as a professor and Beamter (civil servant).

But they had to abandon their strategy three weeks ago when the ministry of science and research in Baden-Württemberg accepted Herrmann's resignation.

Meanwhile, prosecutors in Ulm have been investigating evidence that Herrmann used research papers containing fraudulent data to support his application for his post as professor at the university. But they have suspended their investigations pending clarification of a court ruling in an unrelated case in Berlin.

This case concerns a policeman from east Berlin, who had concealed his former relationship with the Stasi in order to secure employment in the police force in reunified Germany. The court ruled that he should not be disciplined on the grounds that his work since reunification had been satisfactory.

A verdict from Germany's highest court, the Bundesgerichtshof, to which this decision has been appealed, is expected shortly. Because the charges against Herrmann relate to work conducted before he arrived in Ulm, the prosecutors there are waiting for this ruling before deciding whether to proceed.

But Albin Eser, director of the Max Planck Institute for International Criminal Law in Freiburg, who has specialized in scientific fraud, argues that the link between the two cases is not obvious, as the concerns about the policeman as a Stasi informer related to his character, while those about Herrmann related to the way he conducted his job.

Scientists who want to see Herrmann and Brach sanctioned are now pinning their hopes on an investigation by public prosecutors in Berlin, where many of the fraudulent research papers were written, into whether

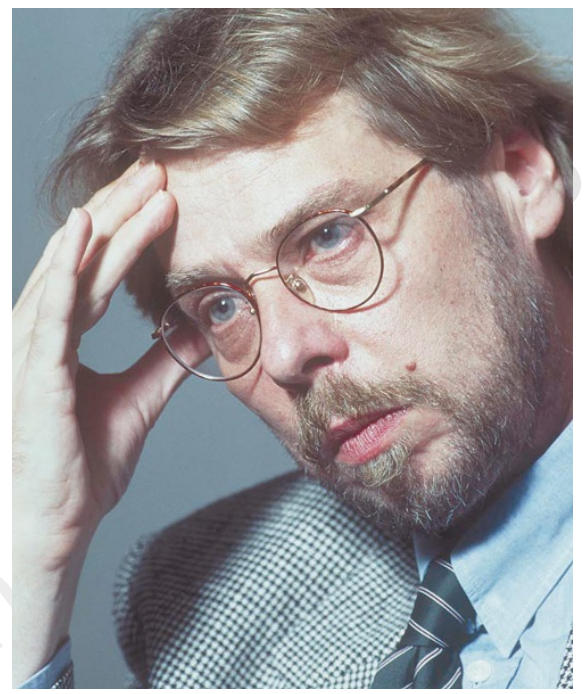

Herrmann: Continues to deny any involvement in misconduct, blaming his collaborator.

the two researchers made false statements to acquire grant money.

The Deutsche Forschungsgemeinschaft (DFG) and the Deutsche Krebshilfe Stiftung (German Cancer Aid Foundation), which between them gave around DM3 million (US\$1.8 million) in research grants to the researchers, have provided documents to help the prosecutors decide whether the success of their grant applications was dependent on fraudulent papers.

The Thyssen Foundation, which awarded a grant of DM200,000 to the pair, has also provided documents to help the prosecutors decide whether the application was copied

\section{Pressure grows for relaxation of French embryo research laws}

[PARIS] French laws banning human embryo research should be eased to allow the use of 'surplus' embryos generated by in vitro fertilization (IVF) procedures, according to the country's national bioethics committee and National Academy of Medicine. But the research should only take place under carefully controlled conditions.

These are the conclusions of reports solicited from the two bodies by Bernard Kouchner, the junior health minister, in the run-up to a revision later this year of France's bioethics legislation. This was adopted in 1994 with the provision that it should be reviewed within five years to take account of changes in science and in society (see Nature 369, 599; 1994).

Current legislation only permits research on a human embryo that does not harm its 'integrity', which in practice puts a ban on embryo research. This contrasts starkly with the position in Britain, where legislation passed in 1990 allows research on embryos less than 14 days old, and embryos can be created specifically for research purposes (see Nature 344, 799; 1990).

As in Britain, much of the opposition to human embryo research in France comes from groups who argue that life begins at fertilization. But there is also considerable support in France for rejecting what is seen as a utilitarian view of human embryos. Axel Kahn, a prominent geneticist and member of the national ethics committee, says that France does not want to go down the British road "where the embryo is a thing until 14 days, and becomes a human after".

The deliberate creation of embryos for research is likewise vigorously rejected by both the academy and the national bioethics committee. The two bodies each recommend limiting any relaxation of the ban to the use of surplus embryos generated by IVF. The national ethics committee adds that such use should require the consent of the parents, while all research projects involving embryos should be individually approved by a national commission.

The report of the working group of the National Academy of Medicine argues that human embryo research is a medical "duty" in that it is required to improve IVF and reproductive medicine. Indeed, some observers argue that the current French ban is hypocritical, as the country's IVF techniques benefit from embryo research carried out elsewhere.

Both groups argue that embryos used for research in vitro should not be reimplanted. Indeed, one loophole in the current French legislation is that, in theory, it would allow research on embryos provided that this was done for the benefit of the fetus and did not interrupt its development.

"In principle, the law allows you to research the effect of drugs and so on with the experimental outcome being the birth of the child; it's terrible," says Kahn, who wants this loophole closed. 
from a Dutch research grant application that Herrmann had been asked to referee.

All three agencies are awaiting the outcome of the Berlin investigation and any possible trial before beginning their own steps to reclaim their money. Such a process could take years. If a trial were to prove that the pair were guilty of fraud, says Christoph Schneider, director for scientific and international affairs at the DFG, it would be a straightforward matter to sue for return of money.

Indeed, in the event of conviction, statesupported grant agencies and charities would be legally obliged to sue for return of grant money. But actually getting the money back would be fraught with difficulty, admits Bruno Zimmermann, the DFG section head who followed the case.

As grant agencies make contracts with institutions rather than individual researchers, the universities where the grant money was spent would presumably have to be sued first, he says. The legal responsibilities have yet to be sorted out, says Zimmermann.

Eser says he is "highly frustrated" with how slowly the case is moving, and is also worried that even if Herrmann's involvement is demonstrated, he may "get away without sanctions". Detlev Ganten, director of the Max Delbrück Centre in Berlin at which Herrmann and Brach worked for several years, is similarly angry at this possibility.

But not everyone is seeking retribution. Guido Adler, dean of medicine at Ulm University, points out that Herrmann is no longer working in academia, and believes that the most important issue is the work of a newly created task force, funded by the DFG, which will assess the scientific impact of the affair and set the record straight (see Box).

\section{Task force set up to determine the damage}

[MUNICH] Determined to assess the full extent of any scientific damage inflicted by the Herrmann and Brach affair (see opposite), the Deutsche Forschungsgemeinschaft (DFG), Germany's main university research funding agency, is funding a task force to pick through the details of around 500 publications that could have been affected

In April, Ulf Rapp, a professor of biology/ immunology at the University of Würzburg, was awarded a one-year grant to conduct the investigation. This will go considerably further than the investigation by a national scientific committee set up jointly last year by the three German institutes where Herrmann and Brach worked.

The national committee had identified 37 papers in which it concluded that data had either certainly or "most probably" been falsified, often by mixing computer-stored images from different experiments to create new figures.

Rapp's team are examining data and figures in all papers published by Herrmann and Brach, and also some published by former colleagues.

They will try to determine which data may have been fabricated or duplicated, and the origin of figures and their primary data. Co-authors on the papers have been asked for relevant information about how figures were created and who generated the data.

Rapp was selected because his field of research overlaps with that of Herrmann and Brach, and also because he returned to Germany in 1994 after 25 years abroad.

"The DFG wanted someone independent to head the task force, and because of my absence I was not part of a local network," Rapp says. The investigation's results will be presented to the DFG next year and may be used in court proceedings. A.A.
Meanwhile Herrmann, who now works in a private medical practice Munich, continues to deny any involvement in misconduct, and sees the failure to bring charges against him as proof of his innocence. He says he is a victim of press harassment which "has harmed my career and destroyed my family".

"Brach was the scientist in the lab: my main and only job in the past ten years has been to care for patients", he says, contradicting the views of many former colleagues that he has always been more of a lab researcher than a clinician. "Now I just want to be left in peace to build up some sort of future."
He could well achieve his goal. The German Chambers of Physicians, which regulate the medical profession, is informed automatically of court convictions - but does not require doctors on their lists to submit details of criminal investigations.

And if Brach is indeed living in New York, she may well avoid a trial because Germany has only an extradition agreement - under which cases are negotiated individually, and the outcome often depends on the severity of the charges - rather than an extradition treaty, in which extradition is automatic on request.

Alison Abbott
IVF drugs cause superovulation, resulting in numerous excess oocytes. Since these cannot be stored frozen, but embryos can, the oocytes are fertilized. France has tens of thousands of these excess embryos in storage. At present, the law only allows for couples who have decided not to conserve their surplus embryos to donate them to a sterile couple, or for unwanted embryos to be destroyed after five years in storage.

Critics such as Kahn argue that it is hypocritical to allow the destruction of surplus embryos but to ban their use for research. "They would be destroyed in any case," he says.

A spokesperson for Jean-François Mattei - a physician who opposes human embryo research and, as a member of parliament (Démocracie Liberale, Bouches-du-Rhône), was the main architect of France's bioethics legislation - agrees that the fate of surplus embryos has raised difficult questions.

But he argues that recent technical



progress in freezing oocytes means that surplus embryos will soon no longer be produced. Kahn argues that this is still "far off", and that the committee's recommendations only relate to the contemporary situation.

Pressure for relaxing the embryo research ban also comes from many scientists within the research agencies. The Centre National de la Recherche Scientifique (CNRS), for example, is discussing with the government how the bioethics laws should be revised to take more account of researchers' other concerns - such as the copious paperwork required for even the most innocuous human genetics research.

Scientists are particularly keen to see the law on embryo research liberalized in order to explore the therapeutic opportunities opened up by progress in cloning and the creation of embryonic stem-cell technologies. The national bioethics committee has already argued that the potential of the latter area is such that it requires a dispensation from the current ban (see Nature 387, 218; 1997).

The current Socialist government is, in principle, likely to be more sympathetic to researchers' needs than its conservative predecessors. 